\title{
A new energy regeneration system for a BLDC motor driven electric vehicle
}

\author{
R. Palanisamy, Rohit Sahasrabuddhe, Mathur Kartik Hiteshkumar, Jay Anil Puranik \\ Department of Electrical and Electronics Engineering, SRM Institute of Science and Technology, Kattankulathur, \\ Chennai, India
}

\begin{tabular}{|c|c|}
\hline Article Info & ABSTRACT \\
\hline Article history: & Amidst the ever-increasing advancements in the technological realm-the \\
\hline Received Jul 17, 2020 & $\begin{array}{l}\text { electrical vehicle industry too has seen several leaps. This particularly owes } \\
\text { to three primary factors one, the fact that we are running out of conventional }\end{array}$ \\
\hline Revised Jan 4, 2021 & resources like petrol and diesel; two, higher efficiency of electric vehicles; \\
\hline Accepted Jan 19, 2021 & $\begin{array}{l}\text { and finally, less pollution caused by them. This has led to a burgeoning in the } \\
\text { use of BLDC motors with electronic commutation not only in EVs but also in }\end{array}$ \\
\hline Keywords: & $\begin{array}{l}\text { industrial and commercial applications. This requires an enhanced driving } \\
\text { and control mechanism to tap the efficiency that such motors provide to }\end{array}$ \\
\hline $\begin{array}{l}\text { BLDC motor } \\
\text { Electric vehicle } \\
\text { Hall sensor }\end{array}$ & $\begin{array}{l}\text { increase performance and to get better controllability and reliability. This } \\
\text { paper presents a controller for this EV motor driver with increased efficiency } \\
\text { by combining various strategies. }\end{array}$ \\
\hline
\end{tabular}

This is an open access article under the CC BY-SA license.

\section{Corresponding Author:}

R. Palanisamy

Department of Electrical and Electronics Engineering

SRM Institute of Science and Technology

Kattankulathur, Chennai, India

Email: krspalani@gmail.com

\section{INTRODUCTION}

Right from the era of invention of vehicles to a time less than five years ago, braking systems in vehicles primarily involve the use of mechanical brakes which use friction and force on the wheels using brake pads to stop the vehicle whilst burning away the energy as heat [1-5]. With the dawn of the era of electric vehicles, the braking system quickly evolved into using the regenerative braking along with the mechanical brakes [6-8]. Unlike mechanical braking, regenerative braking uses the inertia of the rotating wheels to generate electric energy instead of burning it away, thus increasing the range of the vehicle [9-11]. Although it is not as aggressive in braking thus requiring the addition of mechanical brakes for emergency stopping [12].

It is common in electric vehicles to combine both mechanical braking and regenerative braking functions into a single foot pedal: the first part of the foot pedal controls regenerative braking and the final part controls mechanical braking [13, 14]. This is a seamless transition from regenerative braking to mechanical braking, akin to the practice of 'putting the brakes on' in a conventional ICE vehicle [15-17]. In twentieth century, vehicular technology such as control technology and integrative technology have been developing aggressively [18]. Somehow, the limitation of driving mileage still becomes an obstacle for the development of electric vehicles. This problem is exactly what regenerative braking tackles, it has become one of the ways to improve the driving range as this method can increase an EV's driving range by an estimated 8-25\% [19-21]. There are several advantages of regenerative braking taken over the traditional braking system such as: More control over braking, more efficient and effective in stop-and-go driving conditions, prevents wear on 
mechanical brake systems, better fuel economy [22]. This paper presents a speed and regenerative controller design for the BLDC motor drive in an electric vehicle which uses Boolean logic.

\section{PROPOSED SYSTEM CONCEPT}

With the coming up of EVs-the dawn of a new era in the motoring industry, more and more improvements in vehicle technology is on the rise. This naturally led to ways of not only matching the prowess of the combustion engine but, in fact, leaving it behind in so many ways. One of the factors was efficiency. With the introduction of electric motors, several ways to increase efficiency were developed; from different chemical compositions of batteries to regenerative braking.

With more and more EVs being used in real time on the road, this regenerative braking technology has become highly developed. It follows the basic principle of the motor acting as a generator when coasting and feeding this generated electricity back to the battery pack. The prototype developed in this system uses Arduino Nano to control the various aspects involved. The hardware goes hand in hand with the simulation and includes a speed control module made for controlling the speed of the motor when driving which uses inputs from the Hall Effect sensor for feedback.

A regeneration controller, which also uses signals from the Hall sensor is used in the model, this controller comprises of the whole regeneration process and the components it includes. The controller circuits are designed to work with Boolean equation logic. Further, a voltmeter unit is employed which measures and simultaneously displays the regenerative voltage. This helps recharge the battery units used, essentially having a main aim of a better efficiency overall. The Figure 1 shows the basic block diagram of the proposed system.

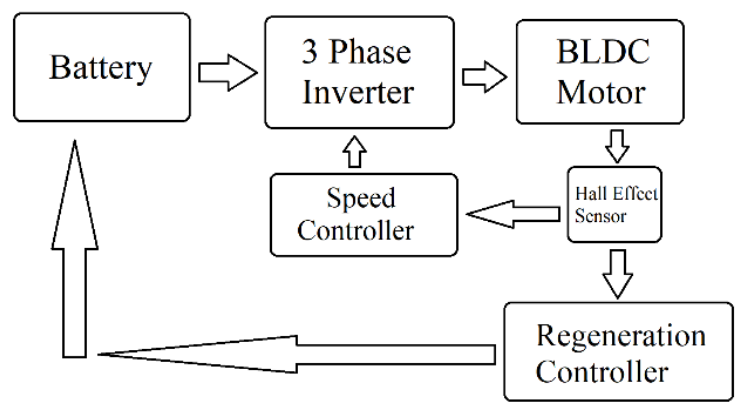

Figure 1. Block diagram of the proposed system

The Simulink model is based on a PMSM motor/generator set is shown in Figure 2, which is usual as for simulation purpose can be used in place of a BLDC. Providing a starting torque, we can get the drive characteristics i.e. the speed stability curve. The battery provides the power to run the drive system. A sixpulse inverter and six-step commutation is used to drive the motor. Hall signals are taken as feedback for deciding the switching sequence of the switched. The inverter converts the DC supply from battery to AC supply to be supplied to the motor. For the speed control curve, a PI controller is used in the simulation model which takes rotor speed as input and gives feedback to the variable voltage supply.

For a motor to work as a generator, it should rotate. Rotation can only be provided if there is no driving torque, i.e. there is no driving force and either a mechanical brake or electric braking is used. As there is no power from the battery, kinetic energy of the motor will keep rotating the rotor due to which the motor will act as a generator and generate an AC output. This AC will be then rectified to DC. This is what is called regenerative braking, which is the main concern of our project.

\subsection{Drive technique}

For the drive part, we are acquiring the hall signals from the in-built hall sensor of the motor [23, 24]. As there are three hall signals, there can be 8 possible combinations in which signals are received. Hall signals can either be a voltage signal or a current signal, but in our case voltage signal is used to determine the switching sequence. But at a given instance neither of the three signals can be in low nor high. At any given instance at least one of the three hall signals will be in high position and one will be in low position. The third will always be in a floating condition, i.e. there will be no voltage in that particular signal. The Figure 3 shows possible combinations of the receiving hall signals and the toggling of switches according to it. 


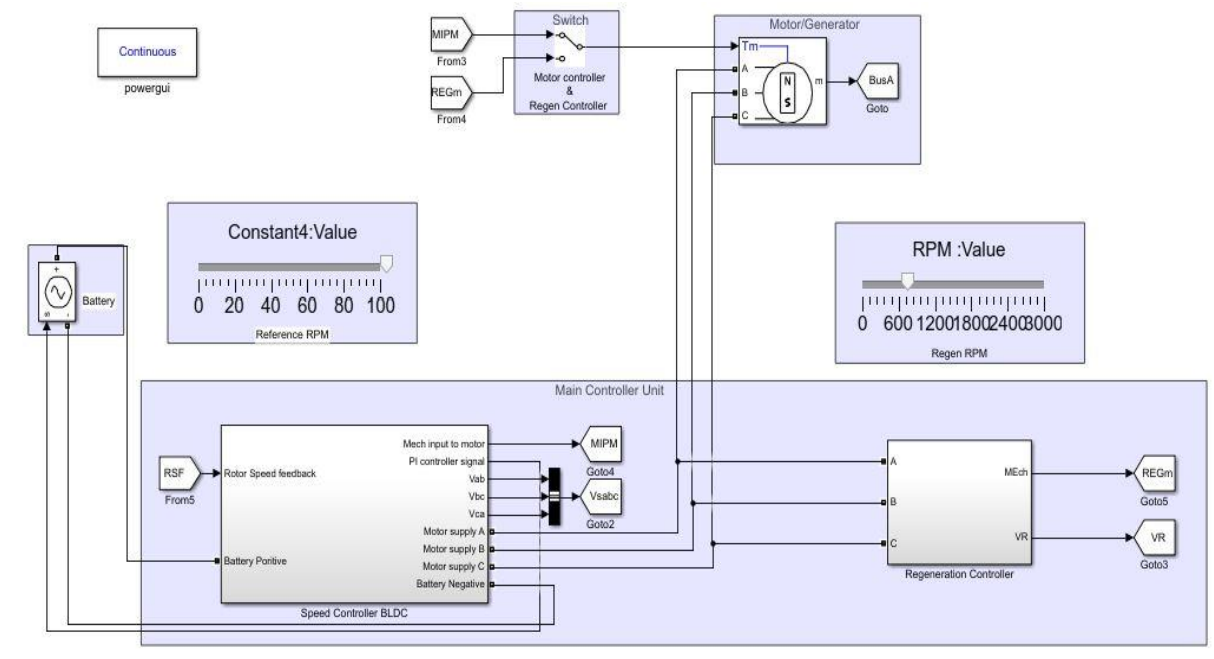

Figure 2. Simulink model is based on a PMSM motor/generator set

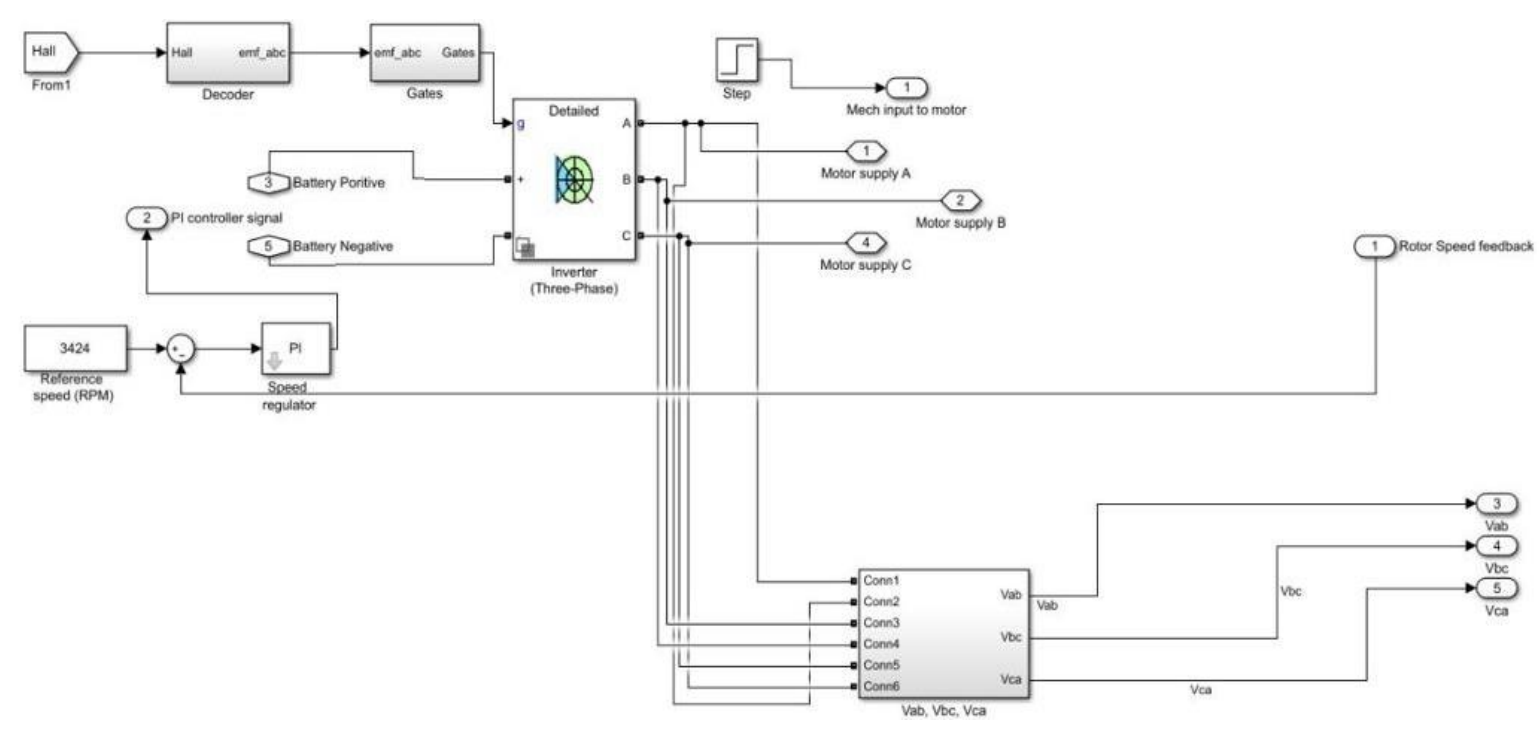

Figure 3. Possible combinations of the receiving hall signals

For the drive part, we are acquiring the hall signals from the in-built hall sensor of the motor. As there are three hall signals, there can be 8 possible combinations in which signals are received. Hall signals can either be a voltage signal or a current signal, but in our case voltage signal is used to determine the switching sequence. But at a given instance neither of the three signals can be in low nor high. At any given instance at least one of the three hall signals will be in high position and one will be in low position. The third will always be in a floating condition, i.e. there will be no voltage in that particular signal. The Table 1 shows the possible combinations of the receiving hall signals and the toggling of switches according to it.

Table 1. Possible combinations of the receiving hall signals and the toggling of switches

\begin{tabular}{|c|c|c|c|c|c|c|c|c|c|c|c|c|c|c|c|}
\hline \multirow[t]{2}{*}{ Phase } & & & & \multicolumn{6}{|c|}{ Switchs } & \multicolumn{3}{|c|}{ Phases } & \multicolumn{3}{|c|}{ Windings } \\
\hline & $\mathrm{H} 3$ & $\mathrm{H} 2$ & $\mathrm{H} 1$ & Q1L & Q1H & Q2L & Q2H & Q3L & Q3H & P1 & $\mathrm{P} 2$ & P3 & $V_{1-2}$ & $V_{2-3}$ & $V_{3-1}$ \\
\hline I & 1 & 0 & 1 & 0 & 1 & 1 & 0 & 0 & 0 & $+V_{m}$ & Gnd & $\mathrm{NC}$ & $-V_{m}$ & - & \\
\hline II & 0 & 0 & 1 & 0 & 1 & 0 & 0 & 1 & 0 & $+V_{m}$ & $\mathrm{NC}$ & Gnd & $m$ & - & $+V_{m}$ \\
\hline III & 0 & 1 & 1 & 0 & 0 & 0 & 1 & 1 & 0 & $\mathrm{NC}$ & $+V_{m}$ & Gnd & - & $-V_{m}$ & - \\
\hline IV & 0 & 1 & 0 & 1 & 0 & 0 & 1 & 0 & 0 & Gnd & $+V_{m}$ & $\mathrm{NC}$ & $+V_{m}$ & - & - \\
\hline V & 1 & 1 & 0 & 1 & 0 & 0 & 0 & 0 & 1 & Gnd & $\mathrm{NC}$ & $+V_{m}$ & - & - & $-V_{m}$ \\
\hline VI & 1 & 0 & 0 & 0 & 0 & 1 & 0 & 0 & 1 & $\mathrm{NC}$ & Gnd & $+V_{m}$ & - & $+V_{m}$ & \\
\hline
\end{tabular}


For determining the switching sequence, first step is to convert the high and low signals from hall sensor to positive and negative voltage signals, which in the simulation is achieved by using AND gates and a generic CONVERT block in Simulink. The AND gate input comprises of combinations of the 3 actual signals with their NOT outputs. Figure 4 shows the switching pulses generated through proposed system.



02
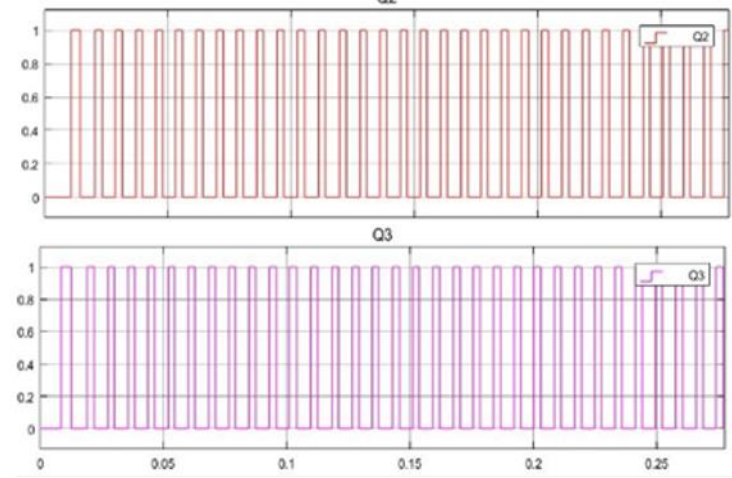
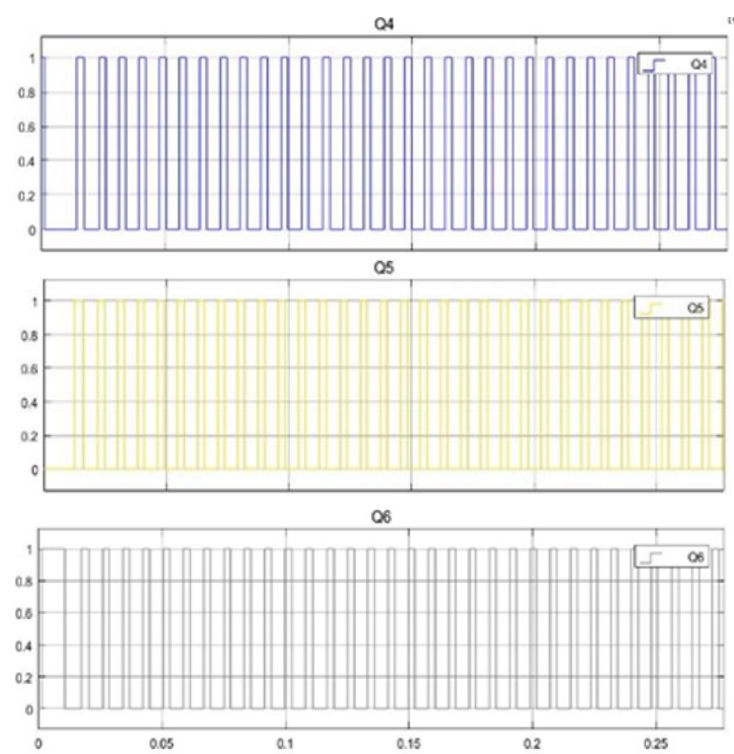

Figure 4. Switching pulses generated through proposed system

\subsection{Regeneration}

The regeneration system can be developed in two ways, either by using a controlled thyristor bridge which also takes the switching signals from the hall sensor, or by using a conventional uncontrolled rectifier design. We opted for a conventional for a conventional rectifier design, as our principle was to keep the system simple and opting for controlled bridge would make the system more complicated. Rather than using a single rectifier, we are using 2 single phase rectifiers in series to boost the output. Though the arrangement does not produce any drastic effect, but is very well significant and divides the load on two single phase rectifiers rather than using one three phase rectifier. Figure 5 shows MATLAB model of rectifier configuration. The two rectifiers have their own filter networks.

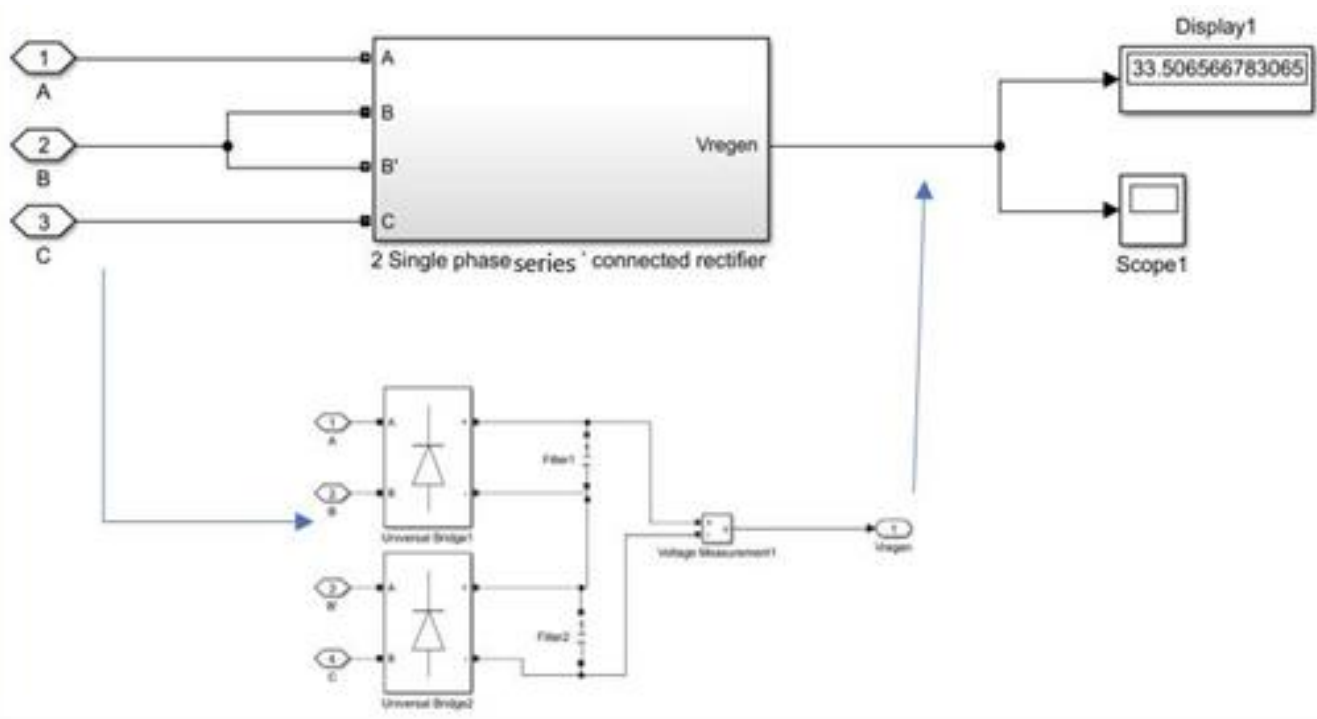

Figure 5. MATLAB model of rectifier configuration 


\section{MOTORING CONCEPT}

Brushless DC electric motor (BLDC motors, BL motors) also known as electronically commutated motors (ECMs, EC motors) are synchronous that is powered by a DC electric source via an integrated inverter/switching power supply, which produces an AC electric signal to drive the motor [25]. In this context, AC, alternating current, does not imply a sinusoidal waveform, but rather a bi-directional current with no restriction on the waveform. Additional sensors and electronics control the inverter output amplitude and waveform (and therefore per cent of DC bus usage/efficiency) and frequency (i.e. rotor speed). Hub motor has greater torque output compared to simple BLDC motor. Further, the weight of the hub motor is also less and doesn't employ a differential for transmission.

A BLDC has a rotor with permanent magnets and a stator with windings. It is essentially a dc motor turned inside out. The brushes and commutator have been eliminated and the windings are connected to the control electronics. The control electronics replace the function of the commutator and energize the proper winding. A brushless dc motor is a polyphase motor with a permanent-magnet rotor. This motor cannot operate without its electronic controller or electronic circuit. Therefore, a brushless DC motor drive system that combines into one unit an AC motor, solid-state inverter and rotor position sensor. The solid-state inverter uses transistor, MOSFETs for low and medium power drives and thyristors for high power drives. The rotor position sensor (RPS) monitor the shaft position and sends the control signals for turning the controlled switches of the inverter in an appropriate sequence.

The motor used in this system has the specifications: voltage rating: $48 \mathrm{~V}$, input power: $1500 \mathrm{~W}$ efficiency: $84.3 \%$, RPM: 744.6, stall current: 45.6 A, no load current: 31.2 A, starting torque: $30 \mathrm{Nm}$ continuous torque: $18 \mathrm{Nm}$. According to the requirements and feasibility, we are using the Kelly $48 \mathrm{~V}$ 1.5 KW BLDC hub motor. A $48.1 \mathrm{~V}$ battery pack is used to power the whole system. The battery system is connected across the Speed Controller for the BLDC Motor. The speed controller employs input from the hall effect sensors which are embedded in the BLDC motor and provide the speed and rotor position. These hall signals are sent to the decoder.

The decoder comprises of Boolean logic to give the appropriate phase outputs to energize the motor terminals in a proper sequence. It contains a NOT gate whose result is de-multiplexed into three signals. These signals are then combined by an AND gate and then sent to a comparator. Three comparator result signals go on to get multiplexed and provide an output signal for each of the phases. Hence, as an example, when the Hall Sensors for the phases A and B are energized, post Boolean solving, B phase is positive and C is negative. The Table 2 shows the phase sequences according to the hall signals.

Table 2. Phase sequences according to the hall signals

\begin{tabular}{cccccc}
\hline ha & hb & hc & emf_a & emf_b & emf_c \\
\hline 0 & 0 & 0 & 0 & 0 & 0 \\
0 & 0 & 1 & 0 & -1 & +1 \\
0 & 1 & 0 & -1 & +1 & 0 \\
0 & 1 & 1 & -1 & 0 & +1 \\
1 & 0 & 0 & +1 & 0 & -1 \\
1 & 0 & 1 & +1 & -1 & 0 \\
1 & 1 & 0 & 0 & +1 & -1 \\
1 & 1 & 1 & 0 & 0 & 0 \\
\hline
\end{tabular}

The Figure 6 shows the signals generated through hall sensor, these emf signals are then demultiplexed into 3 outputs. Each of these 3 outputs is compared with the zero value and the results are multiplexed back to one signal. This resultant signal is the base of the combinations in which the SCRs are energized. The resultant is fed to the six SCRs to form the perfect sequence; for example, when the phases A and $\mathrm{B}$ are positive and negative respectively, SCR's 1 and 4 are switched ON. The Table 3 shows the different combinations of the EMF values according to which the SCRs is are turned on.

Table 3. Combinations of the EMF values according to which the SCRs is are turned on

\begin{tabular}{ccccccccc}
\hline emf_a & emf_b & emf_c & Q1 & Q2 & Q3 & Q4 & Q5 & Q5 \\
\hline 0 & 0 & 0 & 0 & 0 & 0 & 0 & 0 & 0 \\
0 & -1 & +1 & 0 & 0 & 0 & 1 & 1 & 0 \\
-1 & +1 & 0 & 0 & 1 & 1 & 0 & 0 & 0 \\
-1 & 0 & +1 & 0 & 1 & 0 & 0 & 1 & 0 \\
+1 & 0 & -1 & 1 & 0 & 0 & 0 & 0 & 1 \\
+1 & -1 & 0 & 1 & 0 & 0 & 1 & 0 & 0 \\
0 & +1 & -1 & 0 & 0 & 1 & 0 & 0 & 1 \\
0 & 0 & 0 & 0 & 0 & 0 & 0 & 0 & 0 \\
\hline
\end{tabular}



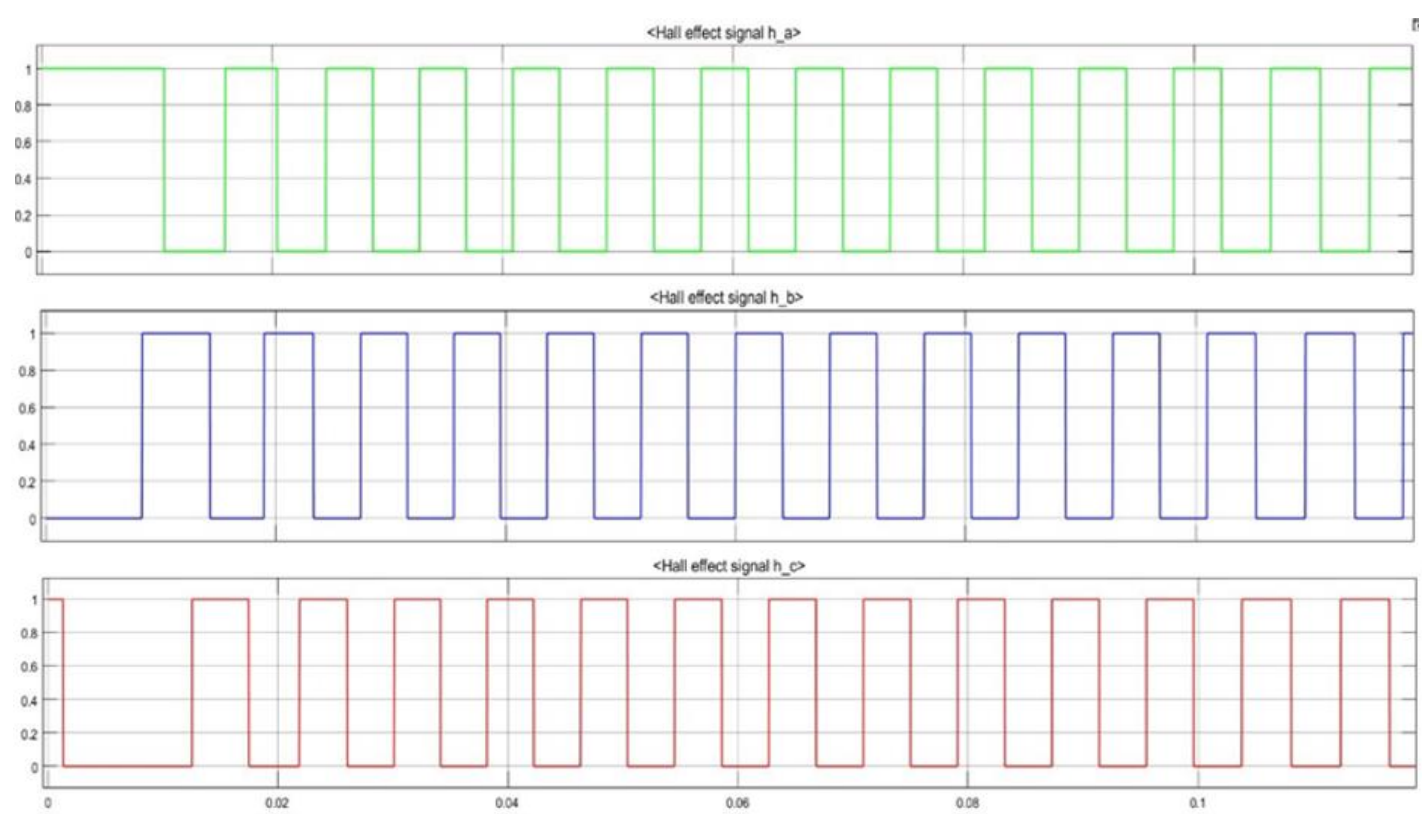

Figure 6. Signals generated through hall sensor

Basically, the SCR pairs in the inverter bridge are fed power from the battery, while the Gate signals to turn them on and off sequentially is provided from the hall sensors embedded in the BLDC Motor according the speed and rotor position. This inverted output is then fed to the motor terminals. The rotor speed (in rpm) feedback input is fed to a comparator as a negative, and the desired (reference) speed as the positive. The difference is sent to a speed regulator and further to a PI controller signal. The PI Controller provides the system the ability to continuously modulate the control.

\section{REGENERATION CONCEPT}

Regeneration of power occurs during the period of coasting. There is no torque input to the motor and then motor only rotates due to inertia. We have used a mechanical switch to toggle the motor terminals to the regeneration controller. The three-phase motor output is fed to the diode bridge rectifier. Each of the three phase outputs of the motor is filtered through a separate LC filter, and further combined so as to provide the regenerated output.

The bridge rectifier receives gating signals from the same Hall Effect sensor system as mentioned earlier. The A, B and C phases of the alternate MOSFETS are connected to enable rectification. After filtration, the final output is measured by a voltmeter connected across both the terminals. A battery may be connected across the same terminals to charge it. When connecting a battery across the terminals after the LC Filter pairs, a diode must be attached in the orientation such that it allows current flow from the regeneration circuit to the battery and no reverse flow is possible.

Calculations:

RPM $\quad=750$

Angular speed, $\mathrm{w}=(2 * \mathrm{pi} * \mathrm{rpm}) / 60=78.5398$

Thus, Power, $\mathrm{P} \quad=\mathrm{T}^{*} \mathrm{w}=3.29 \mathrm{~kW}$

Also, I $\quad=31.25 \mathrm{~A}$

Hence, $\mathrm{V} \quad=\mathrm{P} / \mathrm{I}=105.3 \mathrm{~V}$

Efficiency $\quad=1.21 / 5.16 * 100=24.69 \%$

\section{BATTERY SYSYEM}

A basic requirement for electric vehicles is a portable source of electrical energy, which is converted to mechanical energy in the electric motor for vehicle propulsion. Electrical energy is typically obtained through conversion of chemical energy stored in devices such as batteries and fuel cells. The batteries are made of unit cells containing the chemical energy that is convertible to electrical energy. One or more of these electrolytic cells are connected in series to form one battery. The grouped cells are enclosed in a casing to 
form a battery module. A battery pack is a collection of these individual battery modules connected in a series and parallel combination to deliver the desired voltage and energy to the power electronic drive system.

Cells specification:

Cell voltage $\quad=3.7 \mathrm{~V}$

Cell capacity $\quad=2.6 \mathrm{Ah}$

Battery material $=$ Li-ion

Life cycle $\quad=100$ times

Total battery weight $=15 \mathrm{Kgs}$

Peak current $=130$ A C - Rating-1C

\subsection{Internal configuration of a battery system}

$13 \mathrm{~S} 25 \mathrm{P} 13 \mathrm{~S} 25 \mathrm{P}$ configuration is used. In series the voltage is added up, therefore $13 * 3.7=48.1 \mathrm{~V}$. The total number of cells needed is $25 \times 2.6=26$ cells. The total weight of the system comes out to be 15 Kilograms. Battery calculations:

- Total charging time:

Capacity/charging current=65 Ah/6.5 A=10 hrs.

- Discharge time:

Total discharge time=Battery Capacity/Ampere required

Now the battery capacity can only be utilized up to $80 \%$.

Therefore $80 \%$ of $65 \mathrm{Ah}$ is $52 \mathrm{Ah}$.

- Dissipation rate:

Voltage $=48 \mathrm{~V}$ Input power $=1791.84 \mathrm{~W}$ Output Power $=1000 \mathrm{~W}$

$\eta=$ Output power/Input power $=83.7 \%$

Therefore, dissipation rate $=\frac{1791.84}{48}=37.33 \mathrm{~A}$

- State of charge:

Cell capacity $=80 \%$ of Max cell capacity $=65-52 \mathrm{Ah}=13 \mathrm{Ah}$

- $\quad$ Theoretical stored energy:

Vbat $*$ Capacity $=48 * 65=3120 \mathrm{Wh}$

Lithium Ion battery is the suitable battery for the vehicle.

\section{CONCLUSION}

This work presents a regeneration system for a BLDC motor driven electric vehicle. It makes the use of regeneration principle in electric motors which allows the use of a motor as a generation to capture energy when no torque is applied to the motor. The performance of the system is first tested as a simulation and then applied to hardware. Regeneration increases the vehicle efficiency and range, thus making it highly convenient to operate and use. As given in the regeneration concept. the proposed system gives an efficiency of up to $24 \%$ which is higher as compared to other controllers.

\section{REFERENCES}

[1] M. K. Yoong, et al., "Studies of Regenerative Braking in Electric Vehicle," 2010 IEEE Conference on Sustainable Utilization and Development in Engineering and Technology, Kuala Lumpur, Malaysia, 2010, pp. 40-45.

[2] Amol R. Sutar, G. G. Bhide, J. J. Mane, "Implementation and Study of Bldc Motor Drive System," International Journal of Engineering Sciences and Research Technology (IJESRT), vol. 5, no. 5, pp. 57-64, 2016.

[3] A. Joseph Godfrey and V. Sankaranarayanan, "A new electric braking system with energy regeneration for a BLDC motor driven electric vehicle," an International Journal Engineering Science and Technology, vol. 21, no. 4, pp. 704-713, 2018.

[4] F. Naseri, E. Farjah, and T. Ghanbari, "An efficient regenerative braking system based on battery/supercapacitor for electric, hybrid, and plug-in hybrid electric vehicles with BLDC motor," IEEE Transactions on Vehicular Technology, vol. 66, no. 5, pp. 3724-3738, 2017.

[5] V. U. S. Pola and K. P. Vittal, "Simulation of four quadrant operation and speed control of BLDC motor on MATLAB/SIMULINK," TENCON 2008 - 2008 IEEE Region 10 Conference, Hyderabad, India, 2008, pp. 1-6.

[6] Nesimi Ertugrul and Paul P. Acarnley, "Indirect Rotor Position Sensing in Real Time for Brushless Permanent Magnet Motor Drives," IEEE Transactions on Power Electronics, vol. 13, no. 4, pp. 608-616, 1998.

[7] X. Nian, F. Peng and H. Zhang, "Regenerative Braking System of Electric Vehicle Driven by Brushless DC," IEEE Transactions on Industrial Electronics, vol. 61, no. 10, pp. 5798-5808, 2014.

[8] Akhila M. and Ratnan P., "Analysis of Regenerative Braking In Brushless DC Motor Drive Using Adaptive Neuro Based Fuzzy Inference System," International Journal of Science and Research (IJSR), vol. 02, no. 09, pp. 2019-2021, 2015. 
[9] V. Sindhuja and G. Ranjitham, "Regenerative Braking System of Electric Vehicle Driven By BLDC Motor Using Neuro-Fuzzy and PID," International Journal of Innovative Research in Science, Engineering and Technology (IJIRSET), vol. 3, no. 12, pp. 17847-17854, 2015.

[10] P. J. Grbovic, P. Delarue, P. Le Moigne, and P. Bartholomeus, “A bidirectional three-level dc-dc converter for the ultra-capacitor applications," IEEE Transactions on Industrial Electronics, vol. 57, no. 10, pp. 3415-3430, 2010.

[11] Wanzhong Zhao, Gang Wu, Chunyan Wang, Leiyan Yuc, and Yufang Li, "Energy transfer and utilization efficiency of regenerative braking with hybrid energy storage system," Journal of Power Sources, vol. 427, pp. 174-183, 2019.

[12] Jin-san Kim, Feel-soon Kang, Sun-phil Kim, and Sung-Jun Park, "Bidirectional DC-to-DC converter for motor control unit of electric vehicle," IECON 2015-41st Annual Conference of the IEEE Industrial Electronics Society, Yokohama, Japan, 2015, pp. 000927-000931.

[13] Shinn-Ming Sue, Yi-Shuo Huang, Jhih-Sian Syu and Chen-Yu Sun, "A bi-directional power flow IPM-BLDC motor drive for electrical scooters," 2010 5th IEEE Conference on Industrial Electronics and Applications, Taichung, Taiwan, 2010, pp. 1330-1334.

[14] Fernandez S. G., et al., "Unmanned and autonomous ground vehicle" International Journal of Electrical and Computer Engineering (IJECE), vol. 9, no. 5, pp. 4466-4472, 2019.

[15] Zhengyu Chua, Feng, X., Ouyang, M., Wang, Z., Lu, L., Li, J., and Han, X., "Optimal charge current of lithium-ion battery," Energy Procedia, vol. 142, pp. 1867-1873, 2017.

[16] U. Rao Koleti, C. Z. hang, R. Malik, T. Quang Dinh, and J. Marco, "The development of optimal charging strategies for lithium-ion batteries to prevent the onset of lithium plating at low ambient temperatures," Journal of Energy Storage, vol. 24, 2019, Art. no. 100798.

[17] Lath R., Bharatiraja C., Palanisamy R., Banerji S., Dash S. S., "Hysteresis current controller based transformerless split inductor-NPC-MLI for grid connected PV-System,” Procedia Engineering, vol. 64, pp. 224-233, 2013.

[18] Gaurav A. Chandak and A. A. Bhole, "A review on regenerative braking in electric vehicle," 2017 Innovations in Power and Advanced Computing Technologies (i-PACT), Vellore, 2017, pp. 1-5.

[19] Chun-Liang Lin and Weng-Ching Lin, "ABS control design for two-wheel drive electric vehicles," 2011 Second International Conference on Mechanic Automation and Control Engineering, Inner Mongolia, China, 2011, pp. 1011-1014.

[20] S. Maliye, P. Satapathy, S. Kumar, K. Mahapatra, "Regenerative and Anti-Lock braking system in electric vehicles," 2014 IEEE International Conference on Advanced Communications, Control and Computing Technologies, Ramanathapuram, India, 2014, pp. 1019-1022.

[21] X. Nian, F. Peng, and H. Zhang, "Regenerative Braking System of Electric Vehicle Driven by Brushless DC Motor," IEEE Transactions on Industrial Electronics, vol. 61, no. 10, pp. 5798-5808, 2014

[22] J. Srijeeth, V. C. Thiagarajan, and S. Mohanrajan, "Z-Source Dual Active Bridge Bidirectional AC-DC Converter for Electric Vehicle Applications," 2018 IEEE International Conference on Power Electronics, Drives and Energy Systems (PEDES), Chennai, India, 2018, pp. 1-4.

[23] R. G. Chougale and C. R. Lakade, "Regenerative braking system of electric vehicle driven by brushless DC motor using fuzzy logic," 2017 IEEE International Conference on Power, Control, Signals and Instrumentation Engineering (ICPCSI), Chennai, 2017, pp. 2167-2171.

[24] M. -J. Yang, H. -L. Jhou, B. -Y. Ma, and K. -K. Shyu, "A Cost-Effective Method of Electric Brake With Energy Regeneration for Electric Vehicles," IEEE Transactions on Industrial Electronics, vol. 56, no. 6, pp. 2203-2212,

[25] F. Naseri, E. Farjah, and T. Ghanbari, "An Efficient Regenerative Braking System Based on Battery/Supercapacitor for Electric, Hybrid and Plug-In Hybrid Electric Vehicles with BLDC Motor," IEEE Transactions on Vehicular Technology, vol. 66, no. 5, pp. 3724-3738, 2017. 